\title{
Precautionary assessment and management of dolphinfish in the Caribbean*
}

\author{
ROBIN MAHON ${ }^{1}$ and HAZEL A. OXENFORD ${ }^{2}$ \\ ${ }^{1}$ Fisheries and Environmental Consulting, 48 Sunset Crest, St. James, Barbados. \\ E-mail: rmahon@ caribsurf.com \\ ${ }^{2}$ MAREMP, University of the West Indies, Cave Hill, P.O. Box 64, Bridgetown, Barbados.
}

\begin{abstract}
SUMMARY: Dolphinfish in the Caribbean are fast growing and short-lived, living for about 12 to 18 months in the southern Caribbean and a maximum of 2-3 years in the north of the region. They are believed to be highly migratory, are seasonally abundant, and likely to have a more complex stock structure than the larger oceanic epipelagic species. Most of the information on dolphinfish in the western central Atlantic comes from studies in the waters of the USA and the eastern Caribbean, and there is a general paucity of information particularly for stock-based management of this species. No Caribbean country undertakes regular assessment of dolphinfish, or has put in place any species-specific management program. Yield-per-recruit analyses for this species in the eastern Caribbean suggest that maximization of Y/R is likely to lead to very low levels of mature stock biomass. A stock recruitment analysis does not show any dependency of recruitment on stock size within the observed stock size range. This suggests that recruitment failure could be sudden at some threshold below the minimum observed stock size, probably at about one third of the average observed stock size. Given the trends observed in landings of dolphinfish, a precautionary approach to management is needed for this species in the western central Atlantic. Given the migratory, shared nature of the dolphinfish resource, a regional approach to assessment and management is required. However, the institutional basis for this approach does not currently exist within the region in a form that is functional. The membership of the International Commission for the Conservation of Atlantic Tunas (ICCAT) does not include any of the small island states where dolphinfish is of primary importance. ICCAT would need to establish a regional presence in order to serve the needs of Caribbean states. The FAO Western Central Atlantic Fishery Commission (WECAFC) does not operate in a mode which would allow it to address this issue. The Association of Caribbean States is too new to address it within the near future. Subregional organizations with fisheries programs, such as the Caribbean Community (CARICOM) and the Organisation of Eastern Caribbean States (OECS), represent only a subset of states. However, given the ratification of United Nations Convention on the Law of the Sea (UNCLOS) and the recent International Agreement on Highly Migratory Stocks and Straddling Stocks, these organisations could take the initiative to establish a regional management programme for dolphinfish.
\end{abstract}

Key words: dolphinfish, Coryphaena hippurus, Caribbean, large pelagic.

\section{INTRODUCTION}

Despite its importance, very little effort has been expended by the countries in the Western Central Atlantic on dolphinfish assessment. The most comprehensive work was carried out as a

*Received January 5, 1998. Accepted October 25, 1998. graduate thesis at the University of the West Indies (Oxenford, 1985). In this paper we will review, and in places, expand upon, the efforts that have been made regarding the assessment of dolphinfish. We also present a brief discussion of the need for a regional cooperative approach to dolphinfish management, based to a large extent upon Mahon (1997). 


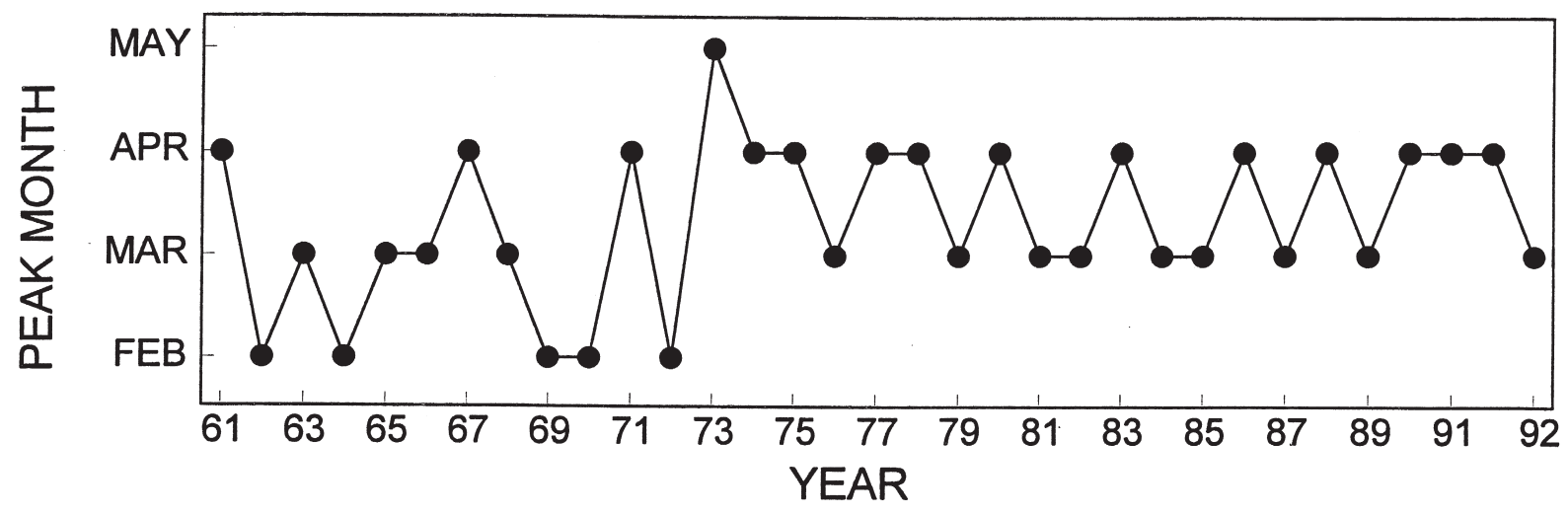

FIG. 1. - The months in which peak dolphinfish catch occurred in Barbados.

\section{ASSESSMENT}

There has not been any comprehensive assessment of dolphinfish in the Western Central Atlantic. However, several studies within the Caribbean have provided information relevant to dolphinfish assessment and management (e.g. Oxenford, 1985; Murray, 1985; Bentivoglio, 1988; Mahon, 1990; Perez and Sadovy, 1991; Rivera Betancourt, 1994), and a preliminary assessment was undertaken for dolphinfish in Barbados by Oxenford (1985). The results of these studies are summarised and/or used below.

There is ongoing work aimed at assessing the status of dolphinfish by the CARICOM Fisheries Resource Assessment and Management Programme (CFRAMP) Resource Assessment Unit in St. Vincent and the Grenadines (Dr. S. Singh-Renton, pers com.). Participating CARICOM countries are being assisted with the collection of catch and effort data. CFRAMP is also collecting length data for dolphinfish in selected eastern Caribbean countries. Another CFRAMP initiative is the promotion of tagging of dolphinfish and other large pelagics by recreational fishers, and some tagging from research vessels as well. The results of these studies will become available over the next 2-4 years.

\section{Indices of abundance}

Dolphinfish are typically taken in the Caribbean by artisanal or small-scale commercial fisheries which exploit several pelagic species on the same trips (Mahon, 1999). Different fishing practices, or even gears may be used on the same trips. The lack of ancillary information needed to apportion effort within trips among types of fishing can be a serious impediment to the use of artisanal catch rates as indices of abundance of a particular species. These catch rate data are frequently only useful in providing rough estimates of seasonality and interannual variability in availability or abundance. However, when dolphinfish are the preferred target species, the catch rates can provide a useful index of abundance. Therefore, interpretation of catch rate timeseries from these types of fisheries must be based on detailed knowledge of the practices and preferences of the fishers.

Similarly, the fact that most medium- to largescale commercial operations in the western central Atlantic are targeting other species (usually large pelagics) means that the catch rates of dolphinfish from those fisheries, even if available, would probably not be good indicators of abundance.

Recreational catch rates may be the best indicators of abundance. However, owing to the strong seasonal nature of dolphinfish availability, and the variability of the season (e.g., Fig. 1), catch rates from tournaments will inevitably be biased according to the point in the seasonal mode in abundance at which the tournament took place. Annual tournaments usually take place at about the same time each year to take advantage of the seasonal peak, but the peak can shift by several weeks. Furthermore, tournament data only show catch of allowable size fish (i.e. above the minimum size set by the tournament), such that the catch of small size fish goes unrecorded. Therefore, recreational catch rates from private sportfishers or from charter boats that fish throughout the season will probably provide better indices of abundance. However, we know of nowhere in the Caribbean where recreational vessels are required to maintain logbooks or report catches.

As a result of the problems discussed above, there are few useful time-series of fishing capacity, or of effort expended in fishing, for large pelagic fishes by domestic artisanal/small-scale fleets in the WECAFC 
Region. The most reliable published time-series of catch rates for dolphinfish in the Western Central Atlantic are presented in Figure 2. Assuming that they reflect reliable indices of abundance of dolphinfish each year, they all indicate marked interannual variability in dolphinfish abundance or availability. The increasing trend in the Barbados fishery is due to increased fishing power in the vessels (see below). There is no apparent monotonic trend in the other time-series, except for that from Venezuela for which the declining trend over the entire period is not significant $(r=-0.364, p=0.105)$. However, from 1967 the decline in catch rate is statistically significant $(r=-0.621, p=0.013)$.

VENEZUELA - RECREATIONAL

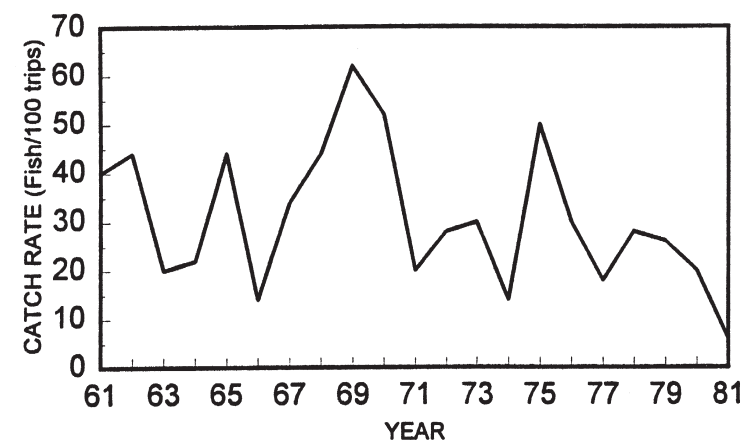

GRENADA - ARTISANAL (Grenville)

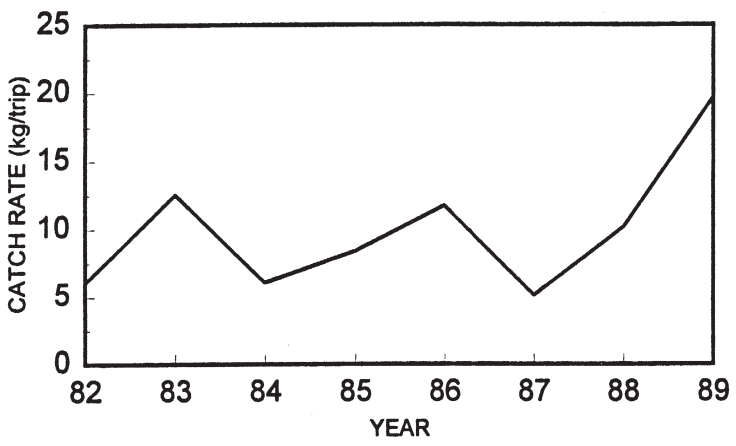

ST. VINCENT -- ARTISANAL (Kingstown)

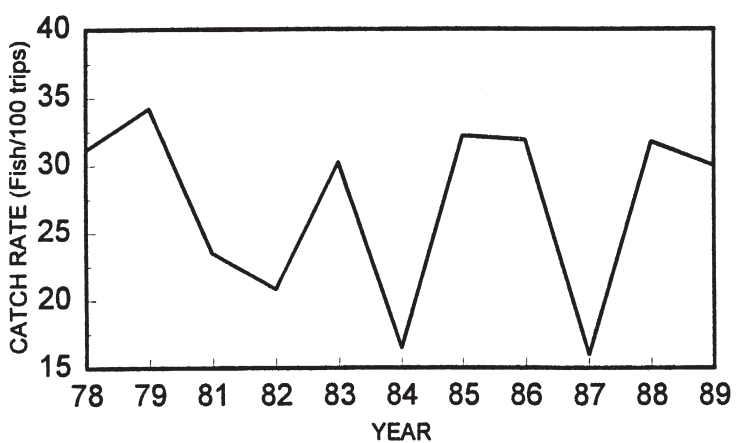

The time-series from the Barbados fishery is based upon launches making one-day trips out of Oistins, a fishing community on the south coast of the island (Oxenford, 1985; Mahon et al., 1990; Collins and Mahon, 1990). Dolphinfish are a preferred species for these vessels and comprised more than $30 \%$ of their landings in the 1980s. This is the longest available time-series in the Caribbean for a relatively large fleet of vessels that is targeting dolphinfish. Owing to its potential value for evaluating trends in abundance, and as input for a stock recruitment analysis, the characteristics of this time-series have been further examined.
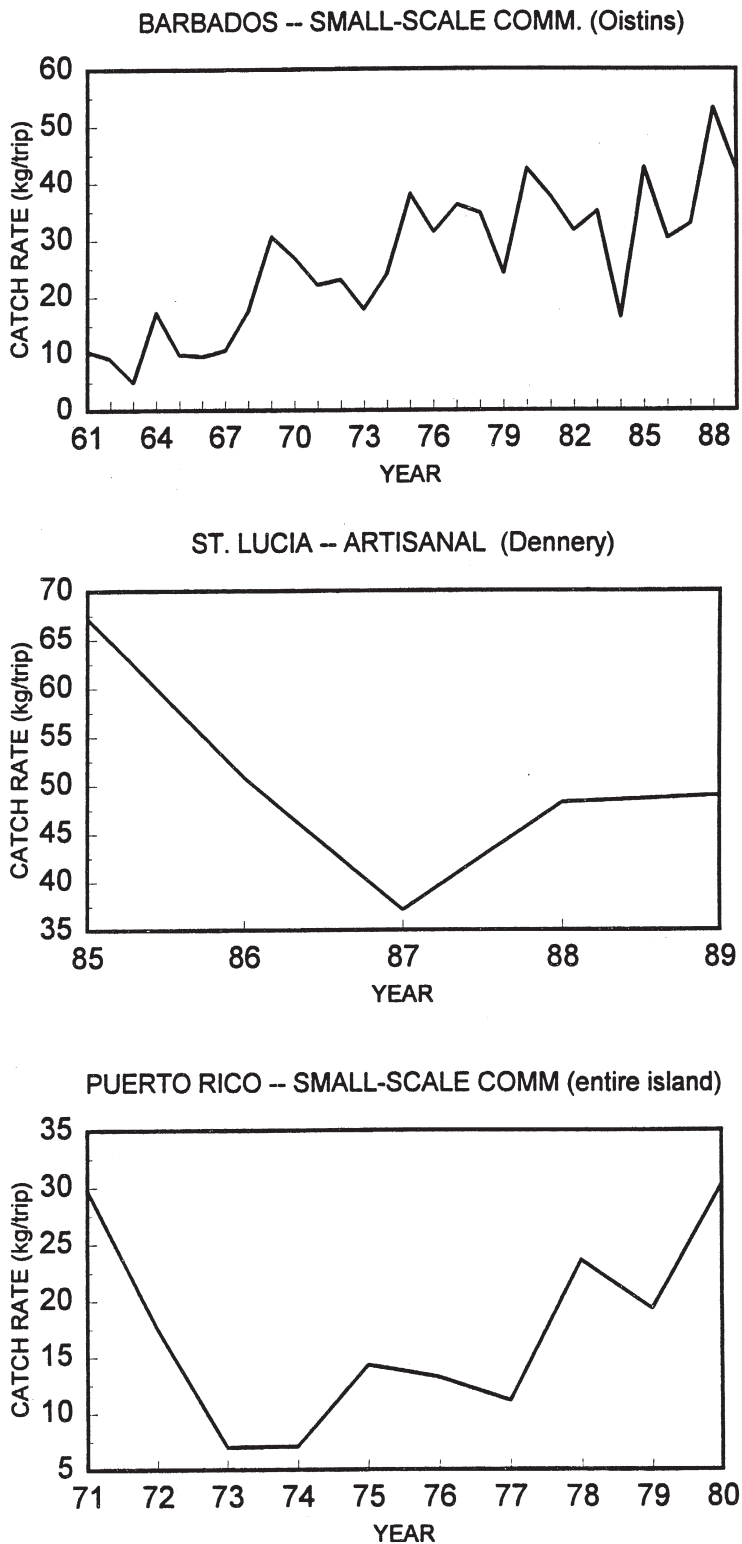

FIG. 2. - Catch rate time-series for dolphinfish in the western Atlantic (Venezuela: Machado and Jaen, 1983; Barbados: this study; Grenada, St. Lucia, St. Vincent: Mahon et al. 1990; Puerto Rico: CFMC 1983). 


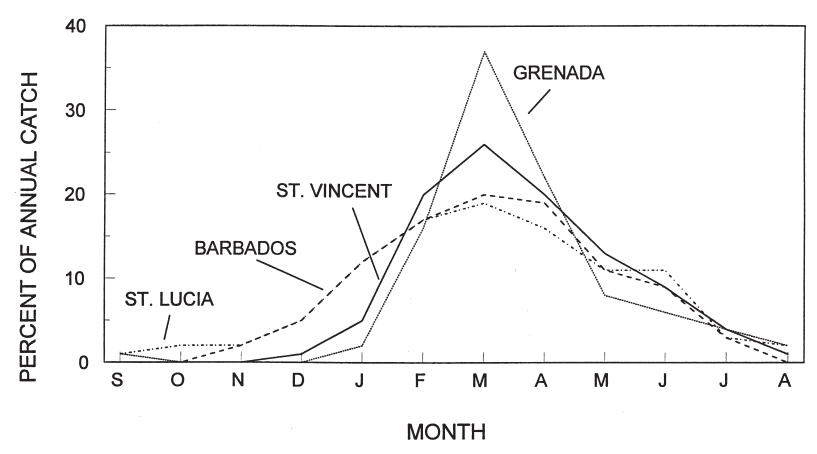

FIG. 3. - The dolphinfish season in four eastern Caribbean countries, from Mahon et al. (1990) (Barbados, 1962-1989; St. Lucia, 1984-1989; St. Vincent, 1979-1989; Grenada, 1981-1989)

Due to the fact that the peak of the dolphinfish season may shift by up to four months from one year to the next (Fig. 1), the effect of seasonality must be considered in deciding upon the best time-period to use for the calculation of annual catch rate. In the eastern Caribbean, the dolphinfish fishing year is best taken from September to the following August. Thus, annual catch rate values are estimated for fishing seasons rather than calendar years (Fig. 3). Several different estimates of annual catch rate calculated from the monthly catch and effort data collected and compiled by the Fisheries Division are shown in Figure 4. The unit of effort is the one-day fishing trip. This is used because, as previously discussed, data are not available to use a more detailed unit of effort, such as hours or line-hours fished.

The pattern shown by these time-series is similar. This increases our confidence in the pattern. The two series that appear to be most similar are: (1) the one based on the sum of the catch for the entire season (September to the following August) divided by the sum of effort for that period (i.e. monthly catch rate weighted by catch), and (2) the one calculated in a similar way for the peak five months.

In view of the increasing trend in catch rate for the Oistins fleet (Fig. 4), Oxenford (1985) evaluated the effects of various vessel characteristics on catch rate. She found that catch rate was positively correlated with vessel size and the duration of a fishing trip. She also found that there was a significant trend of increasing average vessel size between 1962 and 1984. This was considered to be the reason for the increasing trend in catch rate. However, even after the catch rate time-series was detrended using the observed relationship between vessel size and catch/trip, there remained a significant increasing trend in catch/trip. This is probably due to multiplicative effects between vessel size and other ves-

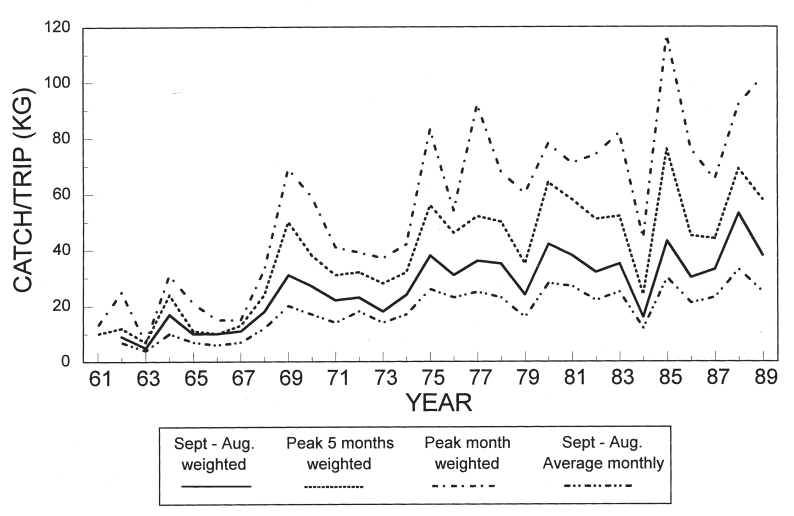

FIG. 4. - Four catch rate time-series for dolphinfish based on the same monthly catch and effort data from Barbados. The first three series are weighted by monthly catch.

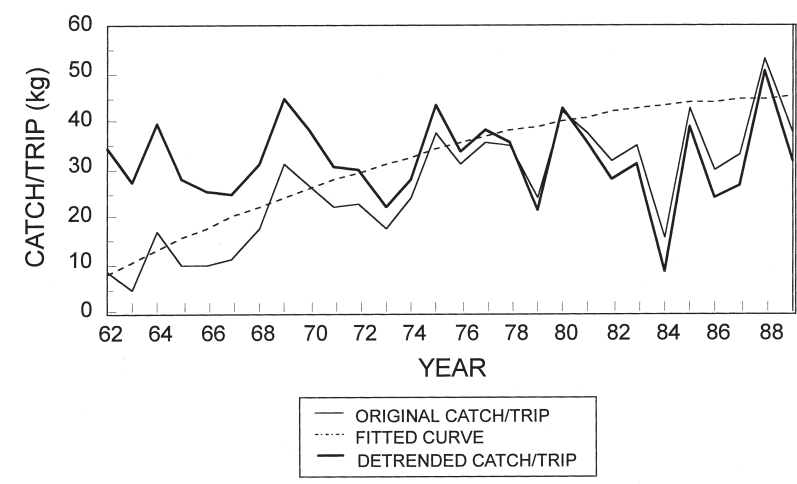

FIG. 5. - Original catch/trip (kg) for dolphinfish by the Barbados fleet, and the detrended catch/trip estimated as the residuals about the fitted curve.

sel characteristics such as horsepower that could not be taken into account in the model. Therefore, in this paper we detrend the time-series by fitting a second order polynomial to the time-series based on a weighted (by catch) mean catch rate for September to August (Fig. 4), and adding the series mean value to the residuals around this fitted line. The detrended series is shown in Figure 5. The catch rate of dolphinfish from Barbados shows a high degree of interannual variability. The coefficient of variation for the detrended series is $27 \%$.

\section{Mortality}

Although several studies have estimated growth for dolphinfish in the Caribbean (Oxenford, 1999), only three report on mortality. Oxenford (1985) used the size composition of the commercial catch in Barbados and size-at-age estimates from daily growth rings in otoliths to construct a catch curve. The estimate of total annual instantaneous mortality (Z) 
from the catch curve was 3.9. Other methods provided similar estimates of $Z$ (Oxenford, 1985). Murray (1985) estimated annual $Z$ as 3.53 from a length converted catch curve for dolphinfish sampled in St. Lucia. This value is similar to the estimate by Oxenford (1985). Bentivoglio (1988) used daily age frequency data from dolphinfish in the Gulf of Mexico to obtain annual $\mathrm{Z}$ estimates between 8.2 and 8.7.

Both Oxenford (1985) and Murray (1985) estimated natural annual instantaneous mortality (M) using Pauly's (1984) equation. As input, Oxenford (1985) used a mean water temperature $\mathrm{T}=28^{\circ} \mathrm{C}$ and von Bertalanffy parameters $\mathrm{L}_{\infty}=155.9 \mathrm{~cm} \mathrm{TL}$, and annual $\mathrm{K}=3.49$, to obtain $\mathrm{M}=2.56$. Murray's input was $\mathrm{T}=27.5^{\circ} \mathrm{C}, \mathrm{L}_{\infty}=236.1 \mathrm{~cm} \mathrm{TL}, \mathrm{K}=0.5322$, from which he estimated $\mathrm{M}=0.66$. Given that Oxenford's growth parameters are estimated from otolith growth rings and that her estimate of $\mathrm{L}_{\infty}$ is consistent with observed maximum sizes of dolphinfish, her estimate of $\mathrm{M}$ is considered to be the most realistic.

\section{Yield per-recruit}

A yield per recruit (Y/R) analysis was carried out for dolphinfish in the eastern Caribbean to determine the feasibility of optimizing $\mathrm{Y} / \mathrm{R}$ as a management objective. Owing to the uncertainties in the input parameters, in particular natural mortality, the analysis should be viewed as exploratory. However, even with the uncertainties, the analysis clearly indicates that $\mathrm{Y} / \mathrm{R}$ is unlikely to be useful as a basis for

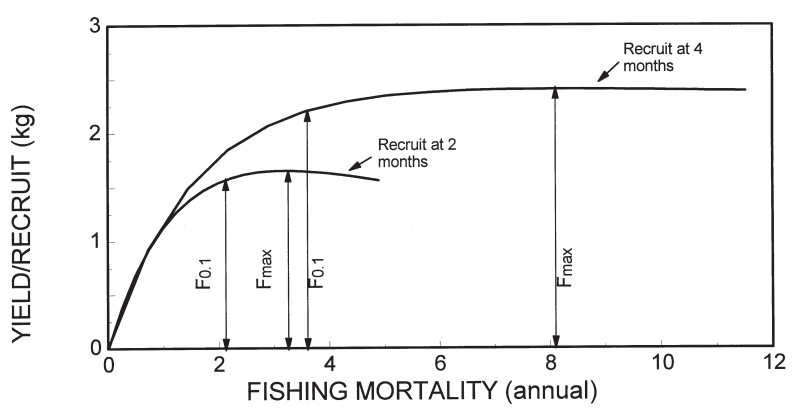

FIG. 6. - Yield per recruit analyses for dolphinfish using input parameters from the Barbados fishery (Oxenford 1985).

a management reference point that can be used by fishery managers.

Oxenford's (1985) von Bertalanffy growth parameters $\left(\mathrm{L}_{\infty}=120.8 \mathrm{~cm} \mathrm{SL}, \mathrm{K}=3.49, \mathrm{t}_{\mathrm{o}}=0.055\right)$ were used to predict lengths for ages 1-12 months. Corresponding weights-at-age were estimated using the weight-standard length relationship provided by Oxenford (1985) for males and females combined: $\mathrm{W}=0.914^{3.08}$. Monthly $\mathrm{M}=0.21$ was used as input.

Two Y/R analyses were carried out by Oxenford (1985) using the method of Thompson and Bell as described by Rivard (1982): one with knife-edge recruitment occurring at age two months; the second with knife-edge recruitment occurring at age four months. Recruitment at age four months was chosen since this is the age at which dolphinfish currently become available to the fisheries in the eastern Caribbean. Recruitment at age two months was also considered since they reach marketable size at this

TABLE 1. - Comparison of cohort biomass estimates for dolphinfish (based on an initial cohort size of 100 fish) when unfished, and when fished at $\mathrm{F}_{0.1}$ and $\mathrm{F}_{\max }$ for two recruitment options.

\begin{tabular}{|c|c|c|c|c|c|c|c|c|}
\hline \multirow{3}{*}{$\begin{array}{l}\text { Age } \\
\text { (months) }\end{array}$} & \multirow{3}{*}{$\begin{array}{l}\text { Standard } \\
\text { length } \\
(\mathrm{mm})\end{array}$} & \multirow{3}{*}{$\begin{array}{l}\text { Weight } \\
\quad(\mathrm{kg})\end{array}$} & \multirow{3}{*}{$\begin{array}{l}\text { Unfished } \\
\text { number of } \\
\text { individuals }\end{array}$} & \multirow{3}{*}{ Unfished } & \multicolumn{4}{|c|}{ Cohort biomass-at-age (kg) } \\
\hline & & & & & \multicolumn{4}{|c|}{ Recruitment at age/target $\mathrm{F}$} \\
\hline & & & & & 2 months/ & 4 months/ & $\begin{array}{l}2 \text { months/ } \\
\mathrm{F}_{0.1}\end{array}$ & 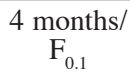 \\
\hline 0 & 0 & 0 & 100 & 0 & 0 & 0 & 0 & 0 \\
\hline 1 & 148 & 0.03 & 81 & 2 & 2 & 2 & 2 & 2 \\
\hline 2 & 429 & 0.79 & 66 & 52 & 52 & 52 & 52 & 52 \\
\hline 3 & 620 & 2.46 & 53 & 131 & 101 & 131 & 131 & 111 \\
\hline 4 & 757 & 4.55 & 43 & 196 & 116 & 196 & 196 & 139 \\
\hline 5 & 857 & 6.67 & 35 & 233 & 106 & 119 & 174 & 139 \\
\hline 6 & 931 & 8.59 & 28 & 244 & 85 & 63 & 135 & 121 \\
\hline 7 & 985 & 10.24 & 23 & 235 & 63 & 31 & 97 & 98 \\
\hline 8 & 1026 & 11.58 & 19 & 216 & 44 & 15 & 67 & 75 \\
\hline 9 & 1056 & 12.66 & 15 & 191 & 30 & 7 & 44 & 56 \\
\hline 10 & 1078 & 13.51 & 12 & 165 & 20 & 3 & 28 & 41 \\
\hline 11 & 1095 & 14.16 & 10 & 141 & 13 & 1 & 18 & 29 \\
\hline \multirow[t]{3}{*}{12} & 1107 & 14.66 & 8 & 118 & 8 & 1 & 11 & 20 \\
\hline & \multirow{2}{*}{\multicolumn{3}{|c|}{$\begin{array}{l}\text { Mature biomass } \\
\text { Percent of unfished mature biomass }\end{array}$}} & 1544 & 369 & 240 & 575 & 579 \\
\hline & & & & & $24 \%$ & $16 \%$ & $38 \%$ & $37 \%$ \\
\hline
\end{tabular}




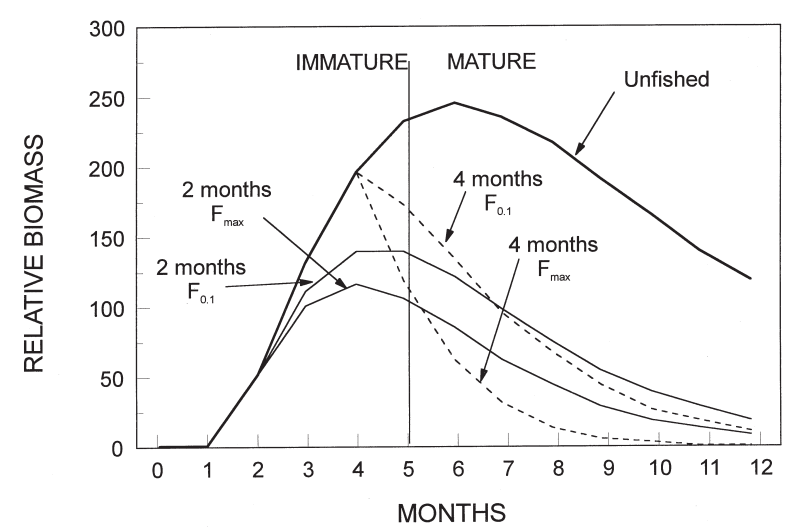

FIG. 7. - Comparison of stock biomass for an unfished dolphinfish cohort, and for a cohort fished at $\mathrm{F}_{\max }$ and $\mathrm{F}_{0.1}$ for recruitment at ages 2 months and 4 months.

age, and could be taken if the fleet travelled further afield to seek them out at that stage of their life history.

The inputs to, and results of the analyses are shown in Table 1, and Figures 6 and 7. Figure 6 shows $\mathrm{Y} / \mathrm{R}$ values at different fishing mortalities $(\mathrm{F})$ for recruitment at ages two and four months. The figure indicates that with recruitment at age two months, Y/R is maximized at an annual $\mathrm{F}$ of 3.17, whereas with recruitment at age four months it is maximized at an annual $F$ of 8.08. Figure 7 shows the distribution of biomass-at-age for an unfished cohort, and for $\mathrm{F}_{\max }$ and $\mathrm{F}_{0.1}$ in each recruitment option. The age of $50 \%$ maturity is taken as 5 months based on maturity/length ogives presented by Oxenford (1985) and Perez and Sadovy (1991). The figure shows that mature biomass in an unfished cohort peaks at age six months.

In Table 1, mature biomass is taken as the sum of biomass for age groups five months and older. The sum of biomass is used because dolphinfish are multiple spawners and probably continue to spawn from the age of maturity until they die.

With recruitment at age two months, fishing at $\mathrm{F}_{\max }$ would result in the reduction of mature biomass down to $24 \%$ of its unfished value (Table 1). With recruitment at age four months, the situation is worse when fishing at $\mathrm{F}_{\max }$ with virtually all of the fish being caught by age seven months. Thus $\mathrm{Y} / \mathrm{R}$ optimization would lead to removal of most fish within two months of maturing. In this situation, the average mature biomass of a cohort would be about $16 \%$ of that for an unfished cohort. Such reductions in mature biomass are likely to be detrimental to recruitment (Mace, 1994), but the potential effects have not been quantified.
Using $\mathrm{F}_{0.1}$ as a target fishing mortality the average mature biomass of a cohort would be $38 \%$ and $37 \%$ respectively, with recruitment at ages two and four months. These values are just below the recommended minimum mature stock biomass of $40 \%$ for situations where the stock recruitment relationship is not well known (Caddy and Mahon, 1995).

The conclusion from these exploratory analyses is that maximization of $\mathrm{Y} / \mathrm{R}$ is unlikely to be an appropriate management objective for dolphinfish in the eastern Caribbean. Management strategies which use $\mathrm{Y} / \mathrm{R}$ as a management criterion, even through the most conservative approach used in this study (recruitment at age 2 months, $\mathrm{F}_{0.1}$ ), will permit the reduction of mature biomass to levels that may result in recruitment failure, or in undesirable interannual abundance fluctuations.

\section{Production modeling}

The Caribbean Fishery Management Council (CFMC, 1983) attempted to fit a surplus production model to catch and effort data for dolphinfish around Puerto Rico. They were unable to estimate MSY because catch rate increased with increasing effort, suggesting that MSY was large relative to current yield. A similar problem was encountered by Oxenford (1985) when attempting to use a detrended catch rate time-series as input to a production model. A further problem with these production models is that they should include total catch for the entire stock.

For an annual species, there will be minimal difference between the MSY estimates from a surplus production model and that from a stock-recruitment model. Any differences between the two will be due only to annual deviations in growth relative to the long term average, caused by environment and density-dependence. Therefore, a stock recruitment approach may be the most appropriate for dolphinfish in the eastern Caribbean, where they are estimated to live for only one year (Oxenford, 1985).

\section{Stock-recruitment relationships}

For an annual species, catch per unit effort in a given year can be used as an index of stock for that year and as an index of recruitment from the previous year's stock. This approach was adopted by Oxenford (1985) who fitted Ricker and BevertonHolt stock recruitment curves to the catch rate time series (1962-1984) from Barbados. Neither model provided an adequate fit. 


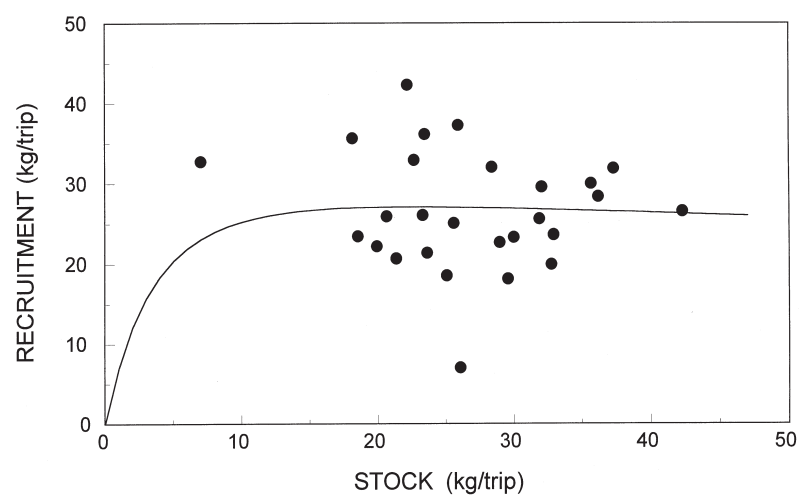

FIG. 8. - Recruitment versus stock for dolphinfish in the eastern Caribbean, based on a detrended catch rate time-series from Barbados. A Shepherd curve is shown.

Using an additional five years of data fully detrended (Fig. 5), and a Shepherd stock-recruitment curve, we re-examined the relationship between stock and recruitment for the Barbados dolphinfish. The plot of recruitment versus stock does not indicate any variation in recruitment over the range of stock sizes observed (Fig. 8). The curve shown in Figure 8 is based on Shepherd's (1982) equation: $\mathrm{R}=\mathrm{aS} /\left[1+(\mathrm{S} / \mathrm{K})^{\beta}\right]$, where $\mathrm{R}$ is recruitment, $S$ is stock and $a, K$ and $\beta$ are constants. This curve was fitted by eye using an iterative process that minimized the sum of squared residuals, while maintaining the condition that there be a lack of trend in recruitment over the range of stock sizes observed. Thus only the shape of the ascending limb of the curve is determined by the fitting procedure. Given the nature of the data, the curve is little more than a reasonable guess at the relationship. Fitting the curve allows for mathematical representation of the relationship, but does not affect our interpretation of it. For the curve shown in Figure 8, $\mathrm{a}=8, \mathrm{~K}=5.2$ and $\beta=4.18$.

The lack of a trend in recruitment over the range of stock sizes observed indicates that at these stock sizes, survival is strongly dependent upon density at some stage during the early (prerecruitment) life-history (Bellows, 1981). The fact that at zero stock size there must be zero recruitment suggests that recruitment may decline sharply at an average stock size that is smaller than the lower end of the observed range. It would appear reasonable, or at least precautionary, to assume that this sharp decline might occur in the area of $10 \mathrm{~kg} /$ trip, or at about onethird of the current average.

\section{Environmental effects on abundance and recruitment}

The high degree of interannual variability in dolphinfish catch rate may be due to the effects of environmental factors on availability or abundance. Oxenford (1985) looked for a correlation between catch rate (1962-1984) and the discharge of the Amazon and Orinoco Rivers, which influence the southeastern Caribbean, but found no significant relationships. Mahon (1990) carried this analysis further, using a longer time-series (1962-1989) and other environmental variables, in addition to the outflow from these rivers. He found significant correlations between various climatic indices and the timing of the dolphinfish season, and between dolphinfish recruitment and the Southern Oscillation Index. Most of these correlations were weak. Since they were based on atmospheric climatic variables rather than oceanic environmental variables, they were interpreted as indicating only that a more thorough examination of the effects of ocean climate on dolphinfish may be worth pursuing.

\section{IMPLICATIONS OF ASSESSMENT FOR MANAGEMENT}

The analyses presented here are based on limited data. However, they represent the best data currently available for dolphinfish. One of the general principles of the Code of Conduct for Responsible Fishing is that "States and subregional and regional fisheries management organizations should apply a precautionary approach widely to conservation, management and exploitation of living aquatic resources [...] taking account of the best scientific evidence available" (FAO, 1995). The Code further states "That the absence of adequate scientific information should not be used as a reason for postponing or failing to take measures to conserve target species, associated or dependent species and non-target species...".

It is in the light of this general principle that we present the available information on dolphinfish, and indicate how that information can guide management until better information becomes available. We consider this point to be of paramount importance, because the biological characteristics of dolphinfish in the eastern Caribbean suggest that with continuation of the current trends in development of the fisheries, there could be a relatively high risk of stock depletion. 
The fact that dolphinfish are frequently caught from schools aggregated under drifting objects with other large pelagics (Gomes et al., 1998), suggests that fishing for them may remain feasible even at very low stock abundance. Thus they would be without the protective mechanism provided by a bioeconomic equilibrium.

Dolphinfish reach a marketable size long before the age of full maturity. Therefore, any shift in the fishery towards smaller fish could result in recruitment overfishing. Thus, a minimum size limit may be appropriate. This approach has already been taken for state waters of Florida and North Carolina in the USA. An alternative would be to limit fishing in areas and times where small fishes are abundant. However, the distribution of dolphinfish at various stages in its life-history is not sufficiently well known for this approach to be implemented.

Dolphinfish exhibit relatively high interannual variability in abundance. There is also a lack of information regarding the relationship between stock and recruitment at low levels of stock abun- dance, and a lack of information regarding environmental effects on dolphinfish recruitment. These suggest that reducing dolphinfish abundance could result in increased variability in recruitment, and could increase the risk that there may be several consecutive years of low abundance.

Mahon (1996, 1999) reports steadily increasing trends in pelagic fishing fleets and landings. He also notes the lack of reporting by many countries that most likely catch considerable quantities of dolphinfish, in particular recreational fisheries and bycatch in large-scale commercial fisheries.

Limited knowledge on landings, the lack of good indices of abundance, and the biological characteristics of the dolphinfish warrant a precautionary approach to setting any management targets (Caddy and Mahon, 1995). Mace (1994) has suggested that in the absence of a known stock-recruitment relationship, a spawning stock biomass (SSB) that is $40 \%$ of the unfished SSB should be a threshold. A similar precautionary threshold could be considered for dolphinfish in the eastern Caribbean.

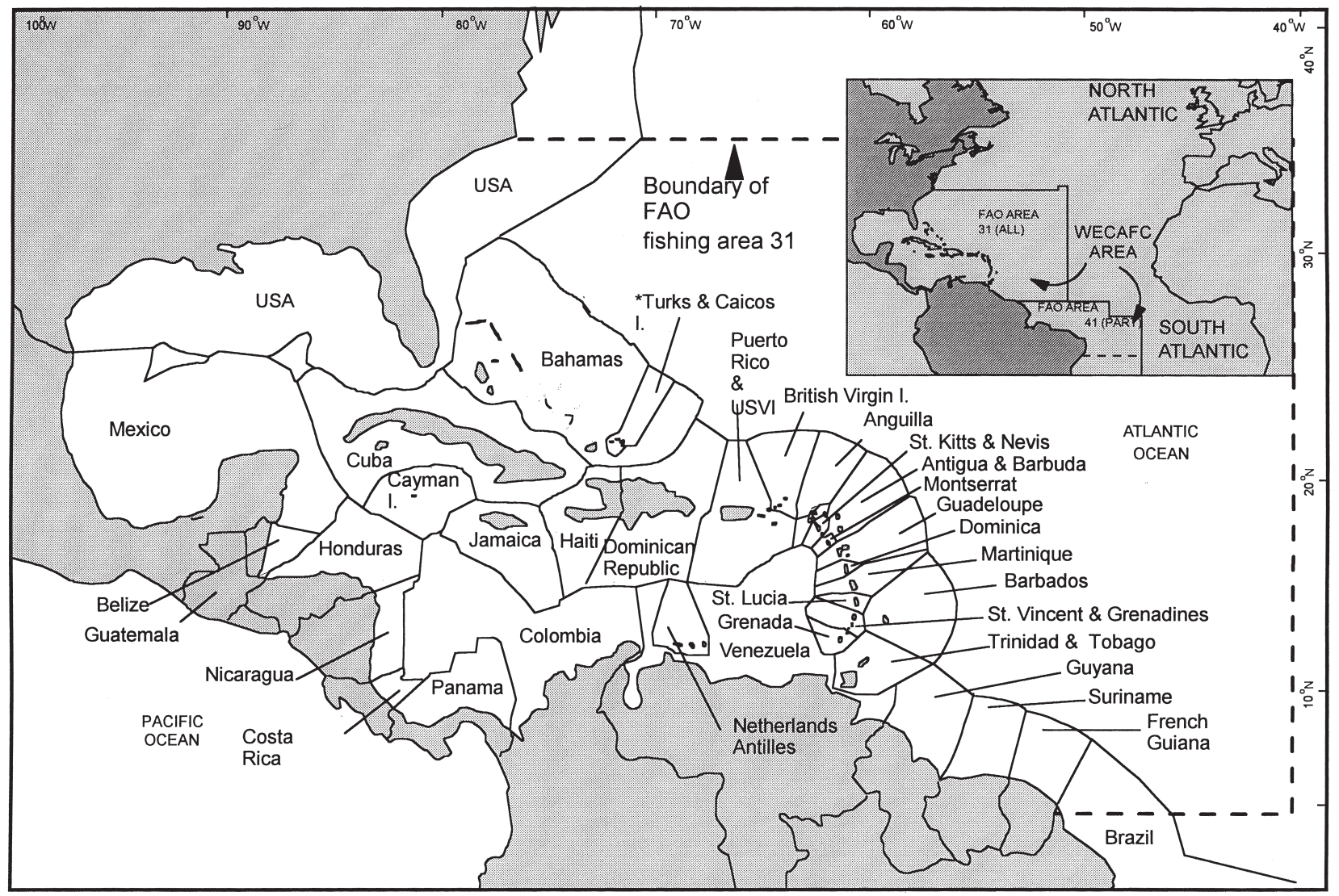

FIG. 9. - The wider Caribbean region and Western Central Atlantic Fishery Commission area showing approximate EEZs of countries (after Mahon, 1996). 


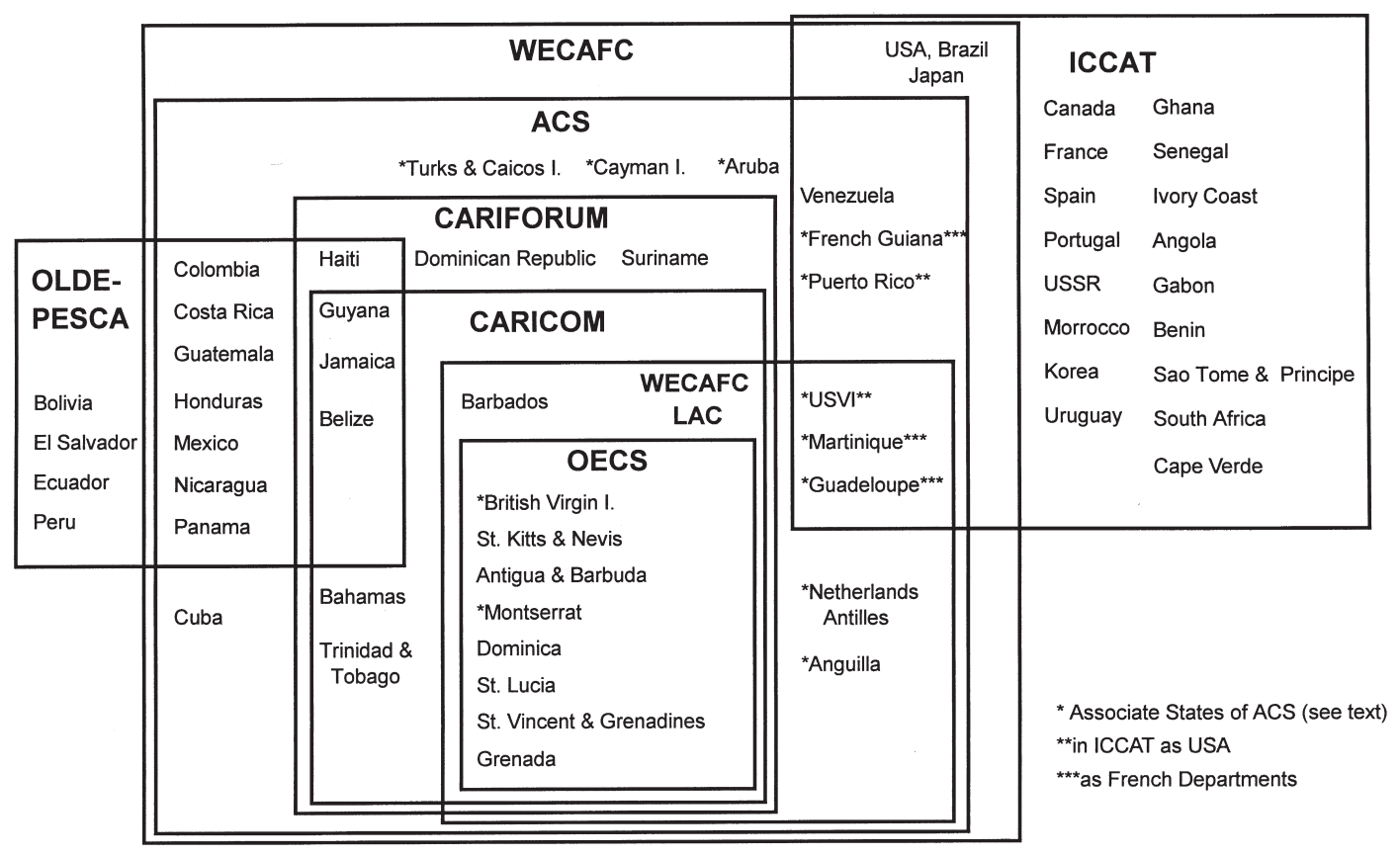

FIG. 10. - The membership of regional and international organisations with responsibility for fisheries management and development in the wider Caribbean $($ WECAFC $=$ FAO West Central Atlantic Fishery Commission, ACS = Association of Caribbean States, CARICOM = Caribbean Community and Common Market, OECS = Organisation of Eastern Caribbean States, LAC = Lesser Antilles Committee, OLDEPESCA = Latin American Organization for Fishery Development, ICCAT = International Commission for the Conservation of Atlantic Tunas).

\section{INSTITUTIONAL ARRANGEMENTS FOR MANAGEMENT}

\section{The management unit}

Stock structure of dolphinfish in the western central Atlantic has not been defined. However, it appears that there may be two or more stocks in the area (Oxenford and Hunte, 1986). Given the seasonal, migratory nature of dolphinfish, and the large number of states within the region, it is clear that the resource will be shared among several countries (Mahon, 1987) (Fig. 9). Therefore, successful management of the resource will require cooperation, as defined by the United Nations Convention on the Law of the Sea (UNCLOS), and elaborated in the International Agreement on Straddling Stocks and Highly Migratory Stocks (United Nations, 1995). Until the stock structure of dolphinfish in the western central Atlantic has been resolved, there should be a region-wide approach to management.

\section{Current management}

Management of fishery resources in the Caribbean region is currently carried out at the national level, by national fisheries departments.
There is minimal cooperation in the management of shared resources (Chakalall et al., 1997). The most notable is a recent effort to establish a Conch Assessment and Management Working Group for the Caribbean (FAO, 1998).

There are several regional and subregional organisations with an interest in fisheries development and management in the Caribbean region (Fig. 10). However, existing institutional mechanisms are not adequate for the management of shared stocks (Mahon, 1996). There is the need to strengthen one or more of the existing institutions to undertake this role, not only for dolphinfish, but for all shared, straddling and highly migratory resources.

The International Commission for the Conservation of Atlantic Tunas (ICCAT), has the mandate to manage tunas and tuna-like resources in the Atlantic. Although not specifically mentioned in the list of species in the basic texts (ICCAT, 1985), dolphinfish would come under the heading of 'associated species'. Few Caribbean countries, however, are active participants in ICCAT, and there is a need for an institution that will focus on assessment and management of shared resources in the western Atlantic, some of which are not large pelagics (Mahon, 1996).

Of existing regional institutions, only the Association of Caribbean States (ACS) and the Western 
Central Atlantic Fishery Commission (WECAFC) have the breadth of membership that would be required for a wide ranging species such as dolphinfish. The ACS is relatively new, and its role in matters such as living resource management is yet to be defined. WECAFC has been in operation since 1976, but has hitherto served only as a forum for exchange of technical information, and has suffered from a lack of commitment on the part of its member countries. Nonetheless, it is the most likely candidate for a strengthened role in assessment and management of shared, straddling and highly migratory fishery resources in the western central Atlantic.

Even if strengthened, WECAFC would probably not be able to function, in the near future, in the same mode as ICCAT regarding setting regulations which would be binding to participating countries. The WECAFC Working Party on assessment of Marine Fishery Resources has recommended that WECAFC be upgraded to enable it to exercise better management over transboundary resources within the region (FAO, 1998). If the WECAFC Commission accepts this recommendation, it will take several years for the transition to become effective, and for member countries to accept the Commission's new role. In the meantime, the most likely mode of operation would be the provision of advice to regional and subregional political groupings, such as the relevant Ministerial Committee of the Caribbean Community (CARICOM)(Mahon, 1997), or to the Caribbean Fisheries Management Council. These organisations would then have to decide if they were willing to adopt the advised measures.

\section{REFERENCES}

Bellows, T.S. Jr. - 1981. The descriptive properties of some models for density dependence. J. Anim. Ecol. 50:139-156.

Bentivoglio, A.A. - 1988. Investigations into the growth, maturity, mortality rates and occurrence of the dolphin (Coryphaena hippurus, Linnaeus) in the Gulf of Mexico. M.Sc. Thesis, University College of North Wales, Bangor, UK, 37 pp.

Caddy, J. F. and R. Mahon. - 1995. Reference points for fisheries management. FAO Fish. Tech. Pap. 347, 83 pp.

CFMC. - 1983. Draft Fishery management Plan, Draft Environmental impact Statement, Regulatory Analysis for the Coastal Migratory Pelagic Resources. Caribbean Fishery Management Council, Hato Rey, Puerto Rico, 195 pp.

Chakalall, B., R. Mahon and P. McConney. - 1997. Current issues in fisheries governance in the Caribbean Community (CARICOM). Marine Policy 22: 29-44.

Collins, T. and R. Mahon. - 1988. The significance of speculator inputs and iceboat landings to the monthly catches at Oistins, Barbados. FAO FI:TCP/RLA/6776 Field Document 1, 6 pp.

FAO. - 1998. Report of the Seventh Session of the WECAFC Working party on Marine Fishery Resources Belize City, Belize, 2-5 December 1997. FAO Fisheries Report No. (in press)

Gomes, C., R. Mahon, W. Hunte, and S. Singh-Renton. - 1998. The role of drifting objects in pelagic fisheries in the southeastern Caribbean. Fish. Res., 34: 47-58.

ICCAT. - 1985. Basic texts. International Commission for the Conservation of Atlantic Tunas, Madrid, Spain, $99 \mathrm{pp}$.

Mace, P. - 1994. Relationships between common biological reference points used as thresholds and targets of fisheries management strategies. Can. J. Fish. Aquat. Sci, 51: 110-122

Machado, G. and R. Jaen. - 1983. General overview of sport fishing in Venezuela. Proc. Gulf. Caribb. Fish. Instit. 35: 179-183.

Mahon, R. - 1987 [ed.]. Report and proceedings of the expert consultation on shared fishery resources of the Lesser Antilles region. FAO Fisheries Report No. 383, 278 pp.

Mahon, R. - 1990. Seasonal and interseasonal variability of the oceanic environment in the eastern Caribbean: With reference to possible effects on fisheries. FAO FI: TCP/RLA/8963 Field Document 5, $45 \mathrm{pp}$.

Mahon, R. - 1996. Fisheries and research for tunas and tuna-like species in the Western Central Atlantic: Implications of the International Agreement on Conservation and Management of Straddling Fish Stocks and Highly Migratory Fish Stocks. FAO Fish Tech. Pap. No. 357, 72 pp.

Mahon, R. - 1997. Approaches to cooperation in fisheries management in the WECAFC area. Prepared for the Meeting of the WECAFC Working party on Marine Resource Assessment, Dec. 2-5, 1997, Belize, 46 pp.

Mahon, R. - 1999. Dolphinfish fisheries in the Caribbean. Sci. Mar., 63(3-4): 411-420.

Mahon, R., F. Murphy, P. Murray, J. Rennie and S. Willoughby. 1990. Temporal variability of catch and effort in pelagic fisheries in Barbados, Grenada, St. Lucia and St Vincent: with particular reference to the problem of low catches in 1989. FAO FI: TCP/RLA/8963 Field Document 2, 74 pp.

Murray, P.A. - 1985. Growth and mortality in the dolphin-fish, Coryphaena hippurus caught off Saint Lucia, W.I. FAO Fish. Rep. No. 327 (Suppl.): 147-151.

Oxenford, H.A. - 1985. Biology of the dolphin, Coryphaena hippurus, and its implications for the Barbadian fishery. Ph.D. Thesis, University of the West Indies, Cave Hill, Barbados, 366 pp.

Oxenford, H.A. - 1999. Biological characteristics of the dolphinfish (Coryphaena hippurus) in the western central Atlantic: a review. Sci. Mar., 63(3-4): 277-301.

Oxenford, H.A. and W. Hunte. - 1986. A preliminary investigation of the stock structure of the dolphin, Coryphaena hippurus, in the Western Central Atlantic. Fish. Bull., 84(2): 451-460.

Pauly, D. - 1984. On the interrelationships between natural mortality, growth parameters and the mean environmental temperature in 175 fish stocks. J. Cons. int. Explor. Mer. 39(2): 175-192.

Perez, R.N. and Y. Sadovy. - 1991. Preliminary data on landings records and reproductive biology of Coryphaena hippurus L., in Puerto Rico. Gulf Caribb. Fish. Instit. 44: in press

Rivard, D. - 1982. APL Programs for stock assessment (revised). Can. Tech. Rep. Fish. Aquat. Sci. No. 1091, 146 pp.

Rivera Betancourt, G.A. - 1994. Age and growth of dolphinfish, Coryphaena hippurus L., in Puerto Rico as determined by otolith analysis. M.Sc. Thesis, University of Puerto Rico, Mayaguez, Puerto Rico, 56 pp.

Shepherd, J.G. - 1982. A versatile new stock-recruitment relationship for fisheries, and the construction of sustainable yield curves. J. Cons. Int. Explor. Mer, 40(1): 67-75.

United Nations. - 1995. Agreement for the implementation of the provisions of the United Nations Convention on the Law of the Sea of 10 December 1982 relating to the conservation and management of straddling fish stocks and highly migratory fish stocks. United Nations Conference on Straddling Fish Stocks and Highly Migratory Fish stocks, 6th session, New York, 24 July- 4 August, 1995, A/CONF.164/37, 40 pp. 